\title{
Pengaruh Infeksi Kecacingan terhadap Kadar Hemoglobin pada Remaja Putri dengan Anemia
}

\author{
Dwi Rahayu' \\ 1.Departemen Gizi, Fakultas Kedokteran UNS, Surakarta \\ Korespondensi : dwi.rahayu.dr@staff.uns.ac.id
}

\begin{abstract}
ABSTRAK
Pendahuluan: Anemia merupakan salah satu masalah kesehatan yang harus dihadapi Indonesia sampai saat ini. Pemerintah telah mencanangkan berbagai program penanggulangan anemia, termasuk pada remaja putri, tetapi prevalensi anemia masih tinggi. Salah satu penyebab turunnya kadar hemoglobin $(\mathrm{Hb})$ adalah infeksi kecacingan, melalui perdarahan saluran cerna dan penurunan asupan makanan. Tujuan penelitian ini adalah mengetahui pengaruh infeksi kecacingan terhadap kadar $\mathrm{Hb}$ pada remaja putri.

Metode: Penelitian ini merupakan penelitian analitik observasional dengan pendekatan case control. Sampel penelitian yang terlibat adalah 46 siswi sekolah menengah atas di Kabupaten Sukoharjo dan terbagi 26 remaja putri dengan anemia dan 20 remaja putri tanpa anemia. Infeksi kecacingan diketahui dari pemeriksaan feses. Semua data dianalisis dengan chi square test dan Independent sampel t- test.

Hasil: Rerata kadar $\mathrm{Hb}$ remaja putri dengan anemia 10,24 $\pm 0,92 \mathrm{~g} / \mathrm{dL}$ dan rerata kadar $\mathrm{Hb}$ remaja putri tanpa anemia $13,07 \pm 0,44 \mathrm{~g} / \mathrm{dL}$. Terdapat 7 remaja putri dengan infeksi kecacingan yang terbagi 2 orang dari kelompok anemia, 5 orang dari kelompok tidak anemia. Akan tetapi secara statistik tidak terdapat hubungan bermakna antara infeksi kecacingan dengan kejadian anemia $(\mathrm{p}=0,11)$. Rerata kadar $\mathrm{Hb}$ remaja putri dengan infeksi kecacingan lebih tinggi baik yang menderita anemia $(11,30 \pm 0,56 \mathrm{~g} / \mathrm{dL})$ ataupun tidak $(13,08 \pm 0,42 \mathrm{~g} / \mathrm{dL})$ dibandingkan dengan kadar $\mathrm{Hb}$ remaja putri tidak kecacingan (anemia 10,37 $\pm 1,06 \mathrm{~g} / \mathrm{dL}$; tidak anemia $=11,34 \pm 1,52 \mathrm{~g} / \mathrm{dL}$ ).

Kesimpulan: Infeksi kecacingan tidak berhubungan dengan kejadian anemia pada remaja putri walaupun kadar $\mathrm{Hb}$ pada infeksi kecacingan lebih tinggi dibandingan kadar $\mathrm{Hb}$ tanpa infeksi kecacingan.
\end{abstract}

Kata Kunci: infeksi kecacingan, hemoglobin, anemia, remaja putri

\begin{abstract}
Introduction: Anemia is one of the health problems in Indonesian. The government has launched anemia prevention programs, including for young women, but the prevalence of anemia is still high. Helminth infections can decrease hemoglobin (Hb) levels through gastrointestinal bleeding and decreased food intake. This study aimed to determine the effect of helminth infections on Hb levels in young women.

Methods: This study was an observational analytic study with a case control approach. Research subject involved of 46 students of senior high school in Sukoharjo Regency and were divided into 26 young women with anemia and 20 young women without anemia. Helminth infection was determined using fecal examination. All collected data were analyzed by Chi square test and Independent sample t-test with $p<0.05$.

Results: The mean of Hb levels in young women with anemia was $10.24 \pm 0.92 \mathrm{~g} / \mathrm{dL}$ and the mean of Hb levels in young women without anemia was 13.07 $\pm 0.44 \mathrm{~g} / \mathrm{dL}$. 7 young women suffered helminth infection, divided into 2 young women with anemia and 5 young women without anemia. However, there was not statistically significant relationship between helminth infection and anemia $(p=0.11)$. The mean of $\mathrm{Hb}$ levels in young women with
\end{abstract}


helminth infection were higher both those who suffered anemia $(11.30 \pm 0.56 \mathrm{~g} / \mathrm{dL})$ or not $(13.08 \pm 0.42 \mathrm{~g} / \mathrm{dL})$ compared with Hb levels in young women without helminth infection (anemia $10.37 \pm 1.06 \mathrm{~g} / \mathrm{dL}$; not anemia $11.34 \pm 1.52 \mathrm{~g} / \mathrm{dL}$ ).

Conclusion: Helminth infection was not related to the incidence of anemia in young women even though Hb levels in helminth infections were higher compared to Hb levels without helminth infections.

Keywords: helminth infections, hemoglobin, anemia, young women

\section{PENDAHULUAN}

Anemia sampai saat ini masih menjadi salah satu masalah kesehatan yang harus dihadapi di seluruh dunia termasuk Indonesia. WHO melaporkan terdapat 2 milyar penduduk dunia yang masih memiliki kadar hemoglobin $(\mathrm{Hb})$ dibawah normal ${ }^{1}$. Hasil riset kesehatan dasar terbaru yang dikeluarkan oleh pemerintah Indonesia melaporkan bahwa terjadi peningkatan prevalensi anemia yaitu 37,1\% ditahun 2013 menjadi $48,9 \%$ ditahun $2018^{2,3}$.

Berbagai program penanggulangan anemia telah dicanangkan oleh WHO maupun pemerintah Indonesia, salah satunya adalah dengan gerakan seribu hari pertama kehidupan dengan pemberian 90 tablet besi pada ibu hamil selama kehamilannya ${ }^{2}$. Sedangkan program khusus yang diterapkan pada remaja putri adalah pemberian 30 tablet tambah darah yang dikonsumsi selama tiga bulan ${ }^{4}$. Program ini melibatkan dinas kesehatan dan puskesmas sebagai penyedia tablet tambah darah serta unit kesehatan sekolah sebagai pelaksana teknis dilapangan. Program lain yang diterapkan untuk mengatasi anemia antara lain fortifikasi makanan dengan zat besi, pemberian profilaksis terhadap malaria serta pemberian obat cacing spectrum luas 5 .

Infeksi kecacingan dapat

menyebabkan anemia karena dapat menyebabkan penurunan asupan makanan dan malabsorpsi nutrisi. Selain itu, perdarahan di saluran cerna karena penempelan cacing pada mukosa usus merupakan penyebab tersering pada anemia karena kecacingan ${ }^{6}$. Indonesia adalah salah satu negara tropis yang memliki prevalensi infeksi kecacingan yang cukup besar yaitu $40-60 \%{ }^{7}$. Berdasarkan hal tersebut, penelitian ini bertujuan untuk mengetahui pengaruh infeksi kecacingan terhadap kadar hemoglobin $(\mathrm{Hb})$ pada remaja putri.

\section{METODE PENELITIAN}

Penelitian ini merupakan penelitian analitik observasional dengan pendekatan case control. Sampel penelitian ini adalah remaja putri yang berasal dari 3 Sekolah Menengah Atas di wilayah Kabupaten Sukoharjo yaitu SMA 1 Weru, SMA 1 Bulu dan SMA 1 Polokarto. Pemilihan sekolah berdasarkan pertimbangan kemungkinan tingginya prevalensi anemia di wilayah tersebut (pedesaan) ${ }^{2}$. Dalam penelitian ini teknik sampling yang digunakan adalah purposive sampling. Remaja putri yang masuk ke dalam sampel penelitian apabila memenuhi kriteria inklusi yaitu: usia 15-19 tahun, tidak sedang menstruasi saat pengambilan sampel darah dan kadar $\mathrm{Hb}<12 \mathrm{~g} / \mathrm{dl}$ untuk kategori anemia serta kadar $\mathrm{Hb} \geq 12 \mathrm{~g} / \mathrm{dl}$ untuk kategori tidak anemia. Kriteria eksklusi pada penelitian ini adalah mendertia penyakit kronis seperti TB paru, malaria, penyakit darah, dan penyakit lain yang mengganggu eritropoesis diketahui dari anamnesis.

Pengambilan darah vena cubiti dilakukan oleh petugas kesehatan dan pemeriksaan kadar $\mathrm{Hb}$ menggunakan metode cyanmethemoglobin yang merupakan metode standart dalam penentuan kadar $\mathrm{Hb}^{8}$. Sedangkan pemeriksaan feses dilakukan dengan menggunakan feses segar di pagi hari untuk menghindari perubahan warna dan bau. 
Semua data yang diperoleh dianalisis menggunakan chi square test dan Independent sampel $t$ - test dengan software SPSS versi 20. Penelitian ini telah mendapatkan persetujuan kelaikan etik dari Komite Etik RS Moewardi dengan nomor: 585/VII/HREC/2017.

\section{HASIL}

Penelitian ini melibatkan 26 subjek penelitian dengan anemia dan 20 subjek penelitian tanpa anemia. Gambar 1 menunjukkan sebaran asal sekolah subjek penelitian. Proporsi terbesar subjek penelitian berasal dari SMA 1 Polokarto (25 siswi) diikuti SMA 1 Weru (16 siswi) dan paling sedikit adalah SMA 1 Bulu (5 siswi).

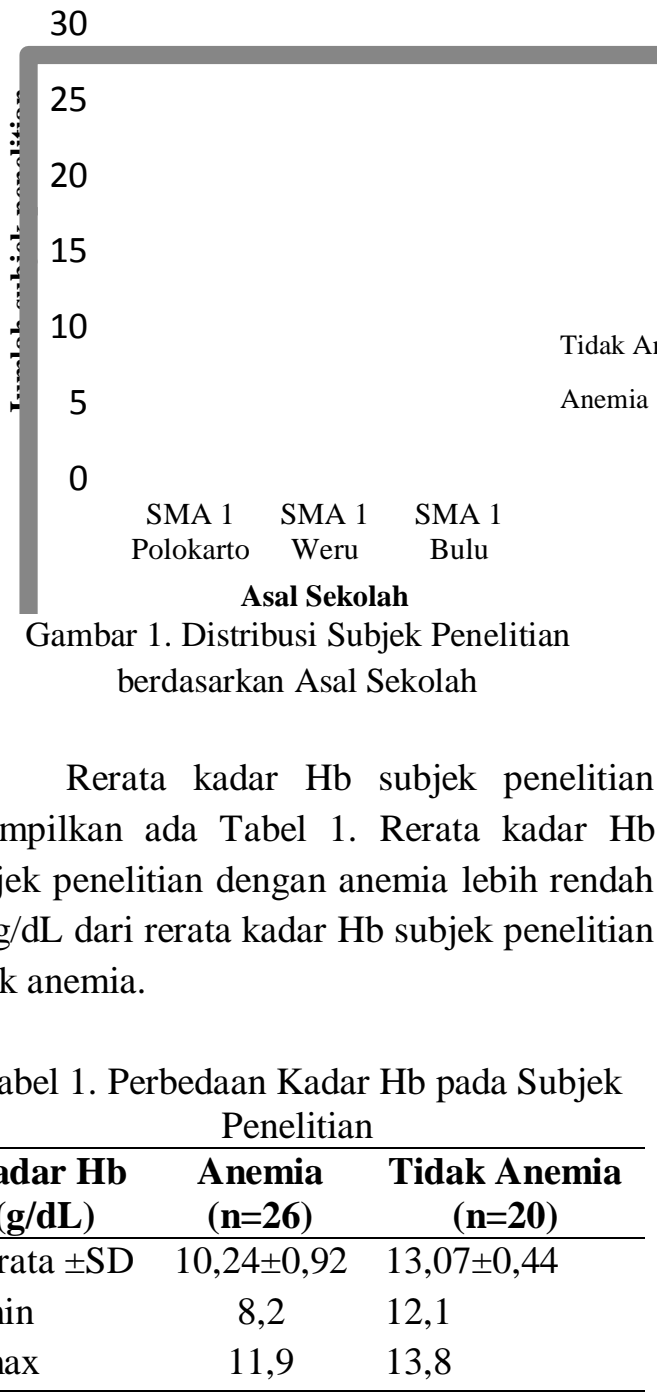

Pemeriksaan infeksi kecacingan dilakukan dengan melihat adanya telur ataupun cacing ascaris, oxyuris ataupun cacing tambang. Empat puluh enam remaja putri yang diperiksa fesesnya didapatkan 7 $(15,21 \%)$ siswi yang hasilnya positif menderita infeksi kecacingan dan 28,6\% dari mereka mengalami anemia. Akan tetapi, secara statistik tidak terdapat perbedaan yang bermakna antara kedua kelompok dengan nilai $\mathrm{p}=0,11$ (Tabel 2). Selain itu, Tabel 2 juga menunjukkan bahwa rerata kadar $\mathrm{Hb}$ subjek penelitian dengan kecacingan lebih tinggi baik yang menderita anemia $(11,30 \pm 0,56 \mathrm{~g} / \mathrm{dL})$ ataupun tidak $(13,08 \pm 0,42 \quad \mathrm{~g} / \mathrm{dL})$ dibandingkan dengan kadar $\mathrm{Hb}$ subjek penelitian tidak kecacingan (anemia $10,37 \pm 1,06 \mathrm{~g} / \mathrm{dL}$; tidak anemia $=11,34 \pm 1,52$ $\mathrm{g} / \mathrm{dL})$. Perbedaan tersebut bermakna secara statistik dengan $\mathrm{p}=0,047$.

Tabel 2. Proporsi Infeksi Kecacingan dan Kadar Hb Subjek Penelitian Anemia dan Tidak Anemia

\begin{tabular}{|c|c|c|c|c|c|}
\hline & & Anemia & $\begin{array}{c}\text { Tidak } \\
\text { Anemia }\end{array}$ & Total & $\begin{array}{c}\mathbf{p} \\
(\mathrm{CI}: 95 \%)\end{array}$ \\
\hline \multicolumn{2}{|c|}{ Kecacingan Ya } & $2(28,6 \%)$ & $5(71,4 \%)$ & $7(100 \%)$ & \multirow[t]{2}{*}{0,114} \\
\hline & Tidak & $24(61,5)$ & $15(38,5)$ & $39(100)$ & \\
\hline \multirow{2}{*}{$\begin{array}{l}\text { Rerata } \\
\text { Kadar Hb } \\
(\mathrm{g} / \mathrm{dL})\end{array}$} & Kecacingan & $11,3 \pm 0,5$ & $13,0 \pm 0,4$ & $12,5 \pm 0,9$ & \multirow[b]{2}{*}{$0,047^{*}$} \\
\hline & $\begin{array}{l}\text { Tidak } \\
\text { kecacingan }\end{array}$ & $10,3 \pm 1,0$ & $12,8 \pm 0,5$ & $11,3 \pm 1,5$ & \\
\hline
\end{tabular}

\section{PEMBAHASAN}

Prevalensi infeksi kecacingan pada remaja putri di Kabupaten Sukoharjo lebih rendah dibandingkan dengan prevalensi infeksi kecacingan di Indonesia yang dilaporkan pada tahun 2002-1009 yaitu sebesar $31,8 \%^{9}$. Hal ini berkaitan dengan program Pemerintah Indonesia melalui Kementerian Kesehatan yang telah berupaya memutus rantai penularan kecacingan melalui kebijakan operasional berupa kerjasama lintas program agar prevalensi kecacingan menjadi $<20 \%$ pada tahun $2015^{10}$. Program yang dicanangkan salah satunya adalah program hidup bersih dan sehat (PHBS) yang 
didalamnya memuat tentang anjuran penggunaan air bersih dan cuci tangan dengan sabun ${ }^{11}$.

Infeksi kecacingan tidak berhubungan dengan kejadian anemia pada remaja putri walaupun pada penelitian ini kadar $\mathrm{Hb}$ remaja putri dengan infeksi kecacingan pada kelompok anemia maupun tidak anemia lebih tinggi dibandingkan dengan kadar $\mathrm{Hb}$ remaja putri tanpa infeksi kecacingan. Sehingga kemungkinan besar infeksi kecacingan bukan sebagai penyebab anemia pada penelitian ini. Infeksi kecacingan hanyalah salah satu dari sekian banyak penyebab anemia. Anemia di Indonesia paling banyak karena defisiensi nutrisi salah satunya defisiensi zat besi ${ }^{12}$. Pada penelitian ini variabel asupan khususnya asupan zat besi ataupun variabel penyebab anemia lainnya seperti variase genetik belum dievaluasi ${ }^{13}$. Selain itu, status kecacingan pada penelitian ini ditegakkan apabila ditemukan telur dan atau cacing ascaris atau oxyuris, tanpa mempertimbangkan jumlah telur dan cacing yang ditemukan dan lamanya periode kecacingan yang akan berdampak pada berapa besar penurunan kadar Hbnya.

Hasil penelitian ini sejalan dengan penelitian pada 129 pekerja tambang di Banjarbaru, menunjukkan bahwa infeksi kecacingan tidak memberikan pengaruh yang signifikan terhadap kejadian anemia ${ }^{14}$. Begitu pula dengan penelitian di Jepang bahwa cacing Trichuris Trichiura tidak berhubungan dengan kejadian anemia ${ }^{15}$. Walaupun penelitian lain yang melibatkan 414 anakanak di Brazil menyebutkan bahwa infeksi kecacingan berhubungan erat dengan kejadian anemia $^{16}$. Oleh karena itu, diperlukan penelitian lebih lanjut dengan sampel yang lebih besar dengan mempertimbangkan faktor-faktor penyebab anemia yang lain.

\section{KESIMPULAN}

Anemia dan infeksi kecacingan masih menjadi masalah kesehatan di Indonesia khususnya di Kabupaten Sukoharjo. Infeksi kecacingan tidak berhubungan dengan kejadian anemia pada remaja putri walaupun kadar $\mathrm{Hb}$ pada infeksi kecacingan lebih tinggi dibandingan kadar $\mathrm{Hb}$ tanpa infeksi kecacingan.

\section{DAFTAR PUSTAKA}

1. World Health Organization. Micronutrient deficiencies. 2015 [sitasi 26 Mei 2015] Diunggah dari: http://www.who.int/nutrition/topics/ida/en

2. Kementerian Kesehatan Republik Indonesia. Riset Kesehatan Dasar 2013. Jakarta: Kemenkes RI; 2013.

3. Kementerian Kesehatan Republik Indonesia. Riset Kesehatan Dasar 2018. Jakarta: Kemenkes RI; 2018.

4. World Healt Organitation. Global Nutrition targets 2025: Anaemia Policy Brief. sitasi 10 Januari 2018] Diunggah dari:

https://www.who.int/nutrition/globaltarget-2025/en/

5. Kementerian Kesehatan Republik Indonesia. Permenkes No. 88 Tahun 2014 tentang Standar Tablet Tambah Darah Bagi Wanita Usia Subur Dan Ibu Hamil. Jakarta: Depkes RI; 2014.

6. Nurdiati DS, Sumarni S, Hakimi M, dan Winkvist A. Impact of intestinal helminth infection on anemia and iron status during pregnancy. Southeast Asian J Trop Med Public Health 2001;32(1).

7. Kementerian Kesehatan Republik Indonesia. Sistem Kesehatan Nasional. 2015 [sitasi 25 Mei 2017] Diunggah dari: http:// www.depkes.go.id.

8. Srivastava $\mathrm{T}$, Negandhi $\mathrm{H}$, Neogi $\mathrm{S} B$, Sharma $\mathrm{J}$ and Saxena R. Methods for hemoglobin estimation: a review of "what works". J Hematol Transfus 2014;2(3): 1028 .

9. Kementerian Kesehatan Republik Indonesia. Pedoman pengendalian cacingan. Jakarta: Kemenkes RI; 2012.

10. Kementerian Kesehatan Republik 
Indonesia Penyakiit kecacingan masih dianggap sepele. 2010 [sitasi 26 Mei 2017] Diunggah dari: www.depkes.go.id/pdf.php?id=1135

11. Kementerian Kesehatan Republik Indonesia. PHBS. 2019 [sitasi 10 Januari 2019] Diunggah dari: http://promkes.kemkes.go.id/phbs

12. Ngui R, Ai Y, Lim L, Kin LC, Chuen CS, dan Jaffar S. Association between anaemia , iron deficiency anaemia , neglected parasitic infections and socioeconomic factors in rural children of West Malaysia, PLOS Negleted Tropical Disease 2012;6(3):1-8.

13. Camaschella C. Iron-deficiency anemia. New England Journal of Medicine 2015;372(19):1832-1843.

14. Sembiring WSRG. Hubungan kejadian infeksi cacing tambang dengan anemia pada pekerja tambang intan tradisional Kelurahan Sungai Tiung Kecamatan Cempaka Kota Banjarbaru tahun 2014. Journalof Health Epidemiology and Commnuicable Disease, 2015;1(1):27-31.

15. Osazuwa F, Ayo OM, dan Imade P. A significant association between intestinal helminth infection and anaemia burden in children in rural communities of Edo state, Nigeria. J Med Sci 2011;3(1):30 34.

16. Zanin FHC, Adalton C, Bonomo É, Teixeira RA, Aparecida C, Benatti K. Determinants of iron deficiency anemia in a cohort of children aged 6-71 months living in the Northeast of Minas Gerais, Brazil 2015:1-14. [sitasi 10 Januari 2019] Diunggah dari: https://doi.org/10.1371/journal.pone.0139 $\underline{555}$ 